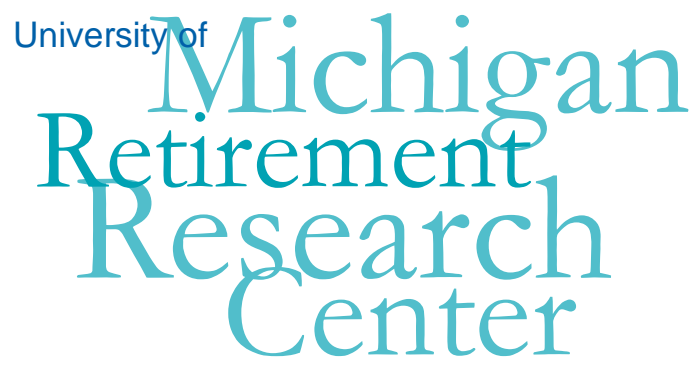

Working Paper

WP 2011-246

\title{
Lifecycle Impacts of the Financial and Economic Crisis on Household Optimal Consumption, Portfolio Choice, and Labor Supply
}

\author{
Jingjing Chai, Raimond Maurer, Olivia S. Mitchell, and Ralph Rogalla
}

\begin{tabular}{|l|l|}
\hline $\mathrm{M}$ & $\mathrm{R}$ \\
\hline $\mathrm{R}$ & $\mathrm{C}$ \\
\hline
\end{tabular}

Project \#: UM11-11 



\title{
Lifecycle Impacts of the Financial and Economic Crisis on Household Optimal Consumption, Portfolio Choice, and Labor Supply
}

\author{
Jingjing Chai \\ Goethe University Frankfurt \\ Raimond Maurer \\ Goethe University Frankfurt \\ Olivia S. Mitchell \\ The Wharton School, University of Pennsylvania \\ Ralph Rogalla \\ Goethe University Frankfurt \\ September 2011 \\ Michigan Retirement Research Center \\ University of Michigan \\ P.O. Box 1248 \\ Ann Arbor, MI 48104 \\ http://www.mrrc.isr.umich.edu/ \\ (734) 615-0422
}

\section{Acknowledgements}

This work was supported by a grant from the Social Security Administration through the Michigan Retirement Research Center (Grant \# RRC 08098401-03-00). The findings and conclusions expressed are solely those of the author and do not represent the views of the Social Security Administration, any agency of the Federal government, or the Michigan Retirement Research Center.

Regents of the University of Michigan

Julia Donovan Darlow, Ann Arbor; Laurence B. Deitch, Bingham Farms; Denise Ilitch, Bingham Farms;

Olivia P. Maynard, Goodrich; Andrea Fischer Newman, Ann Arbor; Andrew C. Richner, Grosse Pointe Park;

S. Martin Taylor, Gross Pointe Farms; Katherine E. White, Ann Arbor; Mary Sue Coleman, ex officio 


\title{
Lifecycle Impacts of the Financial and Economic Crisis on Household Optimal Consumption, Portfolio Choice, and Labor Supply
}

\begin{abstract}
The direct financial impact of the financial crisis has been to deal a heavy blow to investment-based pensions; many workers lost a substantial portion of their retirement saving. The financial sector implosion in turn produced an economic crisis for the rest of the economy via high unemployment and reduced labor earnings, which reduced contributions to Social Security and private pensions. Our research asks which types of individuals were most affected by these dual financial and economic shocks, and it also explores how people may react by changing their consumption, saving and investment, work and retirement, and annuitization decisions. We do so with a realistically calibrated lifecycle framework allowing for time-varying investment opportunities and countercyclical risky labor income dynamics. We show that households near retirement will reduce both short- and long-term consumption, boost work effort, and defer retirement. Younger cohorts will initially reduce their work hours, consumption, saving, and equity exposure; later in life, they will have to work more, retire later, consume less, invest more in stocks, and save more.
\end{abstract}

\section{Authors' Acknowledgements}

The research reported herein was performed pursuant to a grant from the US Social Security Administration (SSA) to the Michigan Retirement Research Center (MRRC) as part of the Retirement Research Consortium. Additional research support was provided by Netspar, the German Investment and Asset Management Association (BVI), and the Pension Research Council at The Wharton School of the University of Pennsylvania. Opinions and errors are solely those of the authors and not of the institutions with whom the authors are affiliated. (C) 2011 Chai, Maurer, Mitchell, and Rogalla. All rights reserved. 


\section{Lifecycle Impacts of the Financial and Economic Crisis on Household Optimal Consumption, Portfolio Choice, and Labor Supply}

\section{Introduction}

Workers are increasingly required to invest in investment-based defined contribution accounts, and then during their golden years, draw down the pension assets in an orderly fashion. Such accounts can help augment and partially replace public pension benefits, as aging economies move toward a better-funded old-age system. Yet the recent financial crisis has raised fresh concerns regarding the risks to which workers are exposed to capital market shocks in these pension systems: for instance, in 2008, U.S. private pension retirement assets declined by onefourth or about US\$2.7 trillion (OECD 2009; Whitehouse 2010). Moreover, the subsequent economic crisis generated rising unemployment and falling labor earnings, with the unfortunate effect of reducing worker contributions to both Social Security and private pension schemes. Indeed, the US unemployment rate of $10 \%$ in 2009 was double that in 2007, with similar high jobless rates in Europe (US BLS, 2010). These combined capital and labor market shocks have made it much more difficult for retirement systems to deliver anticipated old-age benefits. This paper examines how households may be affected by the dual financial and economic crisis such as the one recently experienced.

In particular, we explore how people might react to these shocks, by adjusting their consumption/saving patterns, investment/annuitization paths, work hours, and retirement patterns. Because actual responses are both short- and long-term in nature, some of these will not be observable for several decades to come; furthermore, responses are likely to be heterogeneous. That is, some younger workers may not react much since they have several decades to adjust before they retire, whereas workers on the verge of retirement have little time to adjust their saving, work, and portfolios to offset potential capital and labor market losses. Furthermore, Baby Boomers’ reactions are likely to differ according to individuals' financial wealth and human capital levels. To investigate possible outcomes, we develop a lifecycle model with optimal investment, work hours, retirement, and annuitization decisions, allowing for regime shifts in the investment opportunity set and labor income dynamics.

We build on two strands of literature in our analysis. One set studies how financial market downturns influence older workers' consumption decisions and retirement behavior (Gustman, Steinmeier, and Tabatabai 2010; Hurd and Rohwedder 2010; and Shapiro 2010). Hurd and Rohwedder (2010) as well as Shapiro (2010) point out that the recent financial and economic crisis significantly affected near-retirement households, which seem to have reacted by reducing consumption and working longer. Yet Gustman, Steinmeier, and Tabatabai (2010) 
estimate that retirement will only be postponed by 1.5 months on average, given their simulations of a structural retirement model. Nevertheless due to lack of data, these studies have focused primarily on older persons near retirement and their short-run responses to the recent crises. Thus they do not explore the long-term impact of the crisis on younger age groups, nor do they evaluate consequent changes in asset allocation behavior. Our paper examines these points as we seek to understand how different age groups may adapt along several dimensions, as they react to stock market downturns and unemployment risk.

A second relevant literature has explored household portfolio choice in a discrete time life cycle model with risky capital market returns and uninsurable labor income risk, asking how such uncertainty influences saving, consumption, and asset allocation (Cocco, Gomes, and Maenhout 2005). This literature was extended by Gomes, Kotlikoff, and Viceira (2008) to include flexible hours; subsequent work by Chai et al. (2009) also incorporated flexible retirement and Social Security, as well as the option to annuitize one’s wealth. A key lesson from this research is that wellbeing is greatly enhanced when labor effort is adjustable. Nevertheless, these papers assumed that permanent labor income shocks and risky asset returns were independently and identically distributed over time, while there is now clear empirical evidence refuting this assumption. For instance, Guidolin and Timmerman (2008) show that expected stock market returns and volatility vary both over time and across bull/bear states. That is, in some periods equity returns are characterized by persistently low volatility/high expected returns, whereas in other periods, they are characterized by persistently high volatility/low expected returns. Instead of focusing on stock returns, Caroll and Dunn (1997) and Storesletten, Telmer, and Yaron (2004) estimate a regime-switching model of labor market earnings; they find that the volatility of labor income increases in recessions and falls in expansions.

In what follows, we combine the labor and stock market strands by modeling both timevarying and persistent stock market/labor income processes governed by a Markov chain for the business cycle. Here, some of the time, asset returns are characterized by persistent regimes with an expansive capital market having low volatility/high expected return; in other periods, a contractionary market is characterized by high volatility/low expected returns. In addition, we model the countercyclical dynamics of risky labor income using time-varying shocks on wage rates dynamics and unemployment probabilities driven by the same regime-switching process. Such a setting allows us to explore the situation where a financial sector crisis may also produce an economic crisis (with a time lag), driving high unemployment and lower earnings. In this way, we seek to show how these simultaneous shocks alter retirement, work hours, and consumption trajectories; asset allocation patterns; and annuity purchases of younger and elder 
households. In addition, we can cleanly illustrate the long-term impact of the financial and economic crisis on behavior well into the future. While it is too soon to actually observe how the crisis will alter long-term behaviors, our model provides a useful set of predictions for policy purposes.

Our results indicate that some will be able to hedge adverse capital market developments they face in the crisis, not only by altering their asset allocations, but also by altering their work hours and retirement ages. In particular, we find that when hit by a financial and economic crisis, households near-retirement must cut their consumption both in the short-term and also over the long-term. Moreover, they will have to increase their work effort and postpone retirement. These short-term results correspond to the recent empirical findings noted above. For young cohorts, short-term effects differ from those in the long-run. During the first five years after the onset of the crisis, young households will reduce work hours, savings, and equity exposure and suffer from a drop in consumption. In the long run, however, they will work more, retire later, invest more in stocks, consume less, and save more. These predictions illustrate the key dimensions along which economic adjustment are likely to occur, in response to the most severe recession since the Great Depression.

\section{The Framework}

\subsection{Labor and Capital Markets}

We take as a starting point the presence of dual regimes in capital and labor market dynamics driven by the business cycle. Accordingly, stock returns and labor earnings are modeled as subject to a business cycle governed by a Markov chain process that, following the NBER classification, has two states: expansion and contraction. The variable $s_{t}$ indicates whether at time $t$ the economy is in a state of expansion $\left(s_{t}=0\right)$ or contraction $\left(s_{t}=1\right)$. Transition probabilities between the two business cycle (BC) states are constant over time and defined as $\pi_{i, j}^{B C}:=\mathrm{P}\left(s_{t+1}=j \mid s_{t}=i\right)$, i.e., $\pi_{i, j}^{B C}$ denotes the probability that at time $t+1$ the economy will be in state $j$, given that the economy is in state $i$ at time $t$. Hence, $\pi_{0,1}^{B C}$ represents the probability that state 0 (expansion) will be followed by state 1 (contraction). The unconditional probability for state expansion $\left(s_{t}=0\right)$ is given by $\left(1-\pi_{0,0}^{B C}\right) /\left(2-\pi_{0,0}^{B C}-\pi_{1,1}^{B C}\right)$ and for contraction $\left(s_{t}=1\right)$ by $\left(1-\pi_{1,1}^{B C}\right) /\left(2-\pi_{0,0}^{B C}-\pi_{1,1}^{B C}\right)$, respectively. In what follows, we assume that investors can observe $s_{t}$ and know the state transition probabilities $\pi_{i, j}^{B C}$ at time $t$.

Next, we characterize what we mean by regime shifts in the labor income process, allowing for unemployment risk and state-dependent wage rate dynamics. The worker faces a 
risk of being unemployed in the period $[t, t+1]$, where the probability of unemployment $\pi_{s}^{U}$ is state-dependent and specified as:

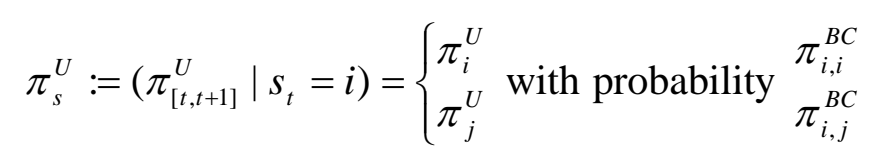

The unemployment probability is lower in expansionary than in contractionary times (i.e., $\left.\pi_{0}^{U}<\pi_{1}^{U}\right)$. At time $t$, the worker must decide what fraction of time $\left(1-L_{t}\right)$ to devote to employment. $L_{t}$ stands for leisure and is measured as a percentage of available time. In each period, if the individual is not unemployed, he receives an after-tax disposable labor income of

$$
Y_{s, t+1}^{E}=\left(1-q_{t+1}\right) \cdot\left(1-t^{l}\right) \cdot W R_{s, t+1} \cdot\left(1-L_{t}\right)
$$

at time $t+1$, where $q_{t+1}$ is the age-dependent deterministic tax-deductible fraction of labor income spent on housing and other durable goods, $t^{l}$ is a proportional tax rate on labor income, and $W R_{s_{t}, t+1}$ is the state-dependent wage rate at time $t+1$, i.e., the income per hour of work effort. The wage rate dynamic process consists of three components as follows:

$$
W R_{s, t+1}=\exp \left(w_{t+1}\right) \cdot E_{s, t+1} \cdot U_{t+1} .
$$

Here $w_{t+1}$ is a deterministic age-dependent function of wage rates that allows us to capture the shape of various empirically-observed earnings profiles, ${ }^{1}$ and $U_{t+1}$ is a state-independent transitory income shock whose logarithm is i.i.d. normally distributed with mean zero and standard deviation $\sigma_{U}$. In addition, $E_{s, t+1}=E_{s, t} n_{s, t+1}$ is a permanent labor earnings component. The logarithm of the permanent income shock $n_{s, t+1}$ is drawn from a Gaussian mixture distribution with mean zero and standard deviation $\sigma_{n, s}$ changing across the two phases of the business cycle. Formally:

$$
\ln \left(n_{s, t+1}\right):=\left(\ln \left(n_{t+1}\right) \mid s_{t}=i\right) \sim\left\{\begin{array}{l}
N\left(0, \sigma_{n, i}\right) \\
N\left(0, \sigma_{n, j}\right)
\end{array} \text { with probability } \begin{array}{l}
\pi_{i, i}^{B C} \\
\pi_{i, j}^{B C}
\end{array} .\right.
$$

To capture countercyclical labor income risk, we set $\sigma_{n, 0}<\sigma_{n, 1}$, such that the volatility in an expansion $\left(s_{t}=0\right)$ is lower than in a contractionary period $\left(s_{t}=1\right) .{ }^{2}$ We also allow for unemployment compensation payments at time $t+1$ worth a specific fraction $v \in(0 ; 1)$ of labor income, i.e., $Y_{s, t+1}^{U}=v \cdot Y_{s, t+1}^{E}$.

In later life, we take the US Social Security system into account and allow for a flexible

\footnotetext{
${ }^{1}$ Bosworth, Burtless and Steuerle (2000) report that middle class workers are likely to have hump-shaped earnings profiles.

${ }^{2}$ Caroll and Dunn (1997) and Storesletten, Telmer, and Yaron (2004) show that permanent labor income risk is strongly countercyclical.
} 
retirement age. According to Social Security rules, the worker may elect to claim Social Security benefit in the window [62, 70] bounded by the 'early' retirement age $(E R A)$ and the late retirement age $(L R A)$. The actual normal retirement age $(N R A)$ is 65 . If the worker claims prior to the NRA, he receives a permanently reduced benefit. Otherwise, the Social Security benefit is increased by the delayed retirement credit. To capture this feature, we calculate the after-tax Social Security benefits as in Chai et al. (2009):

$$
Y_{t}=\left(1-q_{t}\right)\left(1-t^{r}\right)\left(\sum_{t=1}^{K}(1-\bar{L}) \exp (w(t)) / K\right) E_{K} \zeta F_{\tau, N R A}
$$

where $F_{\tau, N R A}=\exp \left(-g_{1}(N R A-\tau)\right) I_{(\tau \leq N R A)}+\exp \left(-g_{2}(N R A-\tau)\right) I_{(\tau>N R A)}$. Here, we assume that when people claim retirement benefits they also consume full leisure simultaneously (as in Chai et al., 2009). ${ }^{3}$ In this way, $\tau$ is the endogenous retirement age and $\zeta$ is the Social Security replacement rate based on lifetime average earnings, and $1-\bar{L}$ stands for the average fraction of available time worked during the work life. The worker's average lifetime earnings level is approximated by $\sum_{t=1}^{K}(1-\bar{L}) \exp (w(t)) / K E_{K}$, where $K$ denotes when the individual attains her normal retirement age under the Social Security rules (NRA). Retirement benefits are taxed at a rate $t^{r} . I$ is an indicator function identifying whether the individual retires at/prior to the NRA, or later. $F_{\tau, N R A}$ is a factor which depends on the NRA and the endogenous retirement age $\tau$. $g_{1}$ and $g_{2}$ are positive constants.

Capital markets include two liquid assets, riskless bonds and risky stocks, and illiquid deferred and immediate fixed payout life annuities. The real bond gross return $R_{f}$ is stateindependent and constant over time, while there is a time-varying investment opportunity set in the stock market. Given a specific state $s_{t}=i$ at time $t$, the risky real log-return on stocks $\ln \left(R_{s, t+1}\right)$ over the period $[t, t+1]$ is drawn from Gaussian mixture distribution with statedependent mean $\mu_{s}$ and standard deviation $\sigma_{s}$, formally:

$$
\ln \left(R_{s, t+1}\right):=\left(\ln \left(R_{[t, t+1]}\right) \mid s_{t}=i\right) \sim\left\{\begin{array}{l}
N\left(\mu_{i}, \sigma_{i}\right) \\
N\left(\mu_{j}, \sigma_{j}\right)
\end{array} \text { with probability } \begin{array}{l}
\pi_{i, i}^{B C} \\
\pi_{i, j}^{B C}
\end{array} .\right.
$$

Each period, investors can observe the state of the economy at time $t$, but the actual probability distribution of returns on stock investments in each period depends on the (unknown) state of the economy at time $t+1$. The (state-dependent) correlation between shocks to permanent earnings

\footnotetext{
${ }^{3}$ Coile et al. (2001) show that a vast majority of workers claim and also stop working at the same juncture. In what follows we abstract from other Social Security rules such as the earnings test for a retiree who returns to work after claiming benefits.
} 
and stock market returns is denoted by $\phi_{s}$.

In addition to stocks and bonds, the investor can, prior to the NRA, purchase fixed payout deferred annuities that provide life-long payments commencing at the NRA. From that point onward, she can purchase additional immediate life annuities. Annuity prices are calculated based on actuarial principles. For a deferred life annuity paying yearly benefits of one from NRA on, the premium is calculated as

$$
h_{t}=(1+\delta) \cdot\left(\prod_{u=t}^{N R A-2} p_{u}^{a}\right) \cdot R_{f}^{-(N R A-1-t)} \cdot \sum_{m=1}^{T-N R A}\left(\prod_{u=K-1}^{N R A-1+m} p_{u}^{a}\right) \cdot R_{f}^{-m} \quad t<N R A
$$

where $p_{u}^{a}$ are the survival probabilities based on the insurer's annuitant mortality table and $\delta$ is the expense loading factor. Accordingly, the premium for an additional immediate life annuity purchased after the NRA is given by

$$
h_{t}=(1+\delta) \cdot \sum_{m=1}^{T-1}\left(\prod_{u=t}^{t+m} p_{u}^{a}\right) \cdot R_{f}^{-m} \quad t \geq N R A
$$

To account for adverse selection, the survival probabilities $p_{u}^{a}$ used in pricing the annuities are typically higher than those of the overall population $\left(p_{u}^{p}\right)$.

\subsection{The Consumer's Life Cycle Problem}

To explore how households might respond to these financial/economic and individual crises, we integrate the decisions to optimally select consumption and saving, asset allocation, work effort and retirement age, and annuitization paths over the lifecycle. We posit that our individual faces an uncertain lifespan and can live for a maximum of $T$ years. Her preferences are characterized by a time additive CRRA utility function $u\left(C_{t}, L_{t}\right)=\frac{1}{1-\rho}\left(C_{t} L_{t}^{\alpha}\right)^{1-\rho}$ defined over the level of non-durable consumption $C_{t}$ and leisure $L_{t}$ at time $t$. After retirement, work hours are equal to zero and leisure is equal to one. The value function is given by:

$$
V_{t}=\frac{\left(C_{t} L_{t}^{\alpha}\right)^{1-\rho}}{1-\rho}+\beta E_{t}\left(p_{t}^{p} V_{t+1}\right)
$$

with terminal utility $V_{T}=\frac{\left(C_{T} L_{T}^{\alpha}\right)^{1-\rho}}{1-\rho}$. The parameter $p_{t}^{p}$ denotes the subjective probability of surviving to time $t+1$, given the consumer is alive at $t$. The parameter $\rho$ is the coefficient of relative risk aversion, and $\beta<1$ is the time preference. Leisure preferences are governed by the parameter $\alpha$. 
Each period, the consumer decides how to allocate her cash on hand $W_{t}$ to bonds $B$, stocks $S_{t}$, annuity purchases $A_{t}$, and consumption $C_{t}$. Her budget constraint is therefore:

$$
W_{t}=S_{t}+B_{t}+A_{t}+C_{t}
$$

and next period's wealth $W_{t+1}$ is given by

$$
W_{t+1}= \begin{cases}\left(S_{t} R_{s, t+1}+B_{t} R_{f}\right)\left(1-t^{c}\right)+t^{c}\left(B_{t}+S_{t}\right)+Y_{t+1} & t<N R A \\ \left(S_{t} R_{s, t+1}+B_{t} R_{f}\right)\left(1-t^{c}\right)+t^{c}\left(B_{t}+S_{t}\right)+P_{t+1}+Y_{t+1} & t \geq N R A .\end{cases}
$$

Here, $P_{t+1}$ is the sum of annuity income received from any previously purchased annuities. Before retirement, $Y_{t+1}$ represents labor income and Social Security benefits afterwards. The recursive evolution equation for the sum of after-tax payout claims at time $t$ from all previous annuities purchased can be written as: ${ }^{4}$

$$
P_{t+1}^{\geq N R A}=\left[P_{t}+\frac{A_{t}}{h_{t}}\right] \frac{\left(R_{f}-1\right)\left(1-t^{c}\right)+1}{R_{f}}
$$

where $A_{t} / h_{t}$ refers to the additional annuity payment purchased in $t .{ }^{5}$ We prevent households from borrowing against human capital and from selling annuities. These restrictions are binding, because otherwise households would engage in highly leveraged stock positions financed by short positions in bonds and/or annuities in order to compensate for their over-investment in human capital when young. Thus, in every year the optimal policy has to satisfy $C_{t}, S_{t}, B_{t}, A_{t} \geq 0$. Moreover, we posit that in order to participate in the stock market, the household has to be willing and able to invest a minimum amount in stocks (as in Smetters and Chen, 2010). This amount is set to $10 \%$ of the permanent labor income after taxes and housing expenditures.

The individual's optimization problem is now to maximize utility as in (7) with respect to her asset allocation between liquid bonds and stocks, illiquid annuities, consumption, work hours, and the retirement decision:

$$
\max _{C_{t}, L_{t}, S_{t}, B_{t}, A_{t}, \tau \in[62,63, \ldots, 70]} V_{t}
$$

Assuming that the consumer knows about the regimes governing the business cycle, there are six state variables: cash on hand $W_{t}$, annuity payouts from previously purchased annuities $P_{t}$, the permanent labor earnings level $E_{t}$, retirement age $\tau$, the business cycle state $\mathrm{s}$, and age t. To reduce the problem by one state variable we normalize the continuous state variables cash on

\footnotetext{
${ }^{4}$ We assume that the annuities are held in non-tax qualified accounts and interest earnings are taxed as capital gains. Chai et al. (2009) show that this is a reasonable approximation to the exclusion ratio approach implemented by the US tax authority, and adopted here for greater computational tractability (Brown et al., 1999).

${ }^{5}$ Prior to the retirement period, this state variable records the amount of payouts starting from the normal retirement age (NRA), from all previously-purchased deferred annuities. After the NRA, this state variable denotes the sumof payouts frompreviously purchased immediate and deferred annuities.
} 
hand with the permanent labor earnings component. Next we discretize the (normalized) continuous state variables and solve the optimization problem by backward induction. ${ }^{6}$

\subsection{Model Calibration}

For the base case, preference parameters are set to standard values in the life cycle literature: the coefficient of relative risk aversion is $\rho=5$ and the discount factor $\beta=0.97$. The leisure preference value $\alpha$ is set equal to 1.3. The one-period survival rate $p_{t}^{s}$ is calculated by the US 1996 population 2000 table for females; the lifespan is modeled from age 20 to $100(T=81)$. To estimate the business cycle transition matrix, we take US Gross National Product (GNP) growth from the Bureau of Economic Analysis (BEA) for 1929-2006 with Datastream data for the years 2007-2008. ${ }^{7}$ A contraction (expansion) state occurs when the GNP growth rate was less than (greater than) its sample period mean (as in Storesletten, Telmer, and Yaron 2004). In this way, we estimate the transition matrix to be of the following form: $\left[\begin{array}{ll}0.68 & 0.32 \\ 0.32 & 0.68\end{array}\right] \cdot{ }^{8}$ A process with such a transition matrix is more likely to stay in the same state rather than to move to the other state, since probabilities $p_{1,1}$ and $p_{0,0}$ are greater than 0.5 . The deterministic component of the wage rate process follows Fehr, Jokisch, and Kotlikoff (2006), reflecting middle-income households, and it is scaled to generate an average gross labor income of 20,000 dollars at age 20. In what follows, we assume an available time of 100 waking hours per week and set the minimum leisure time to $L_{\min }=1 / 3$, in other words, the maximal labor supply is $2 / 3$ of available time. The average labor supply $1-\bar{L}$ used to calculate Social Security benefits is equal to 0.4 , which corresponds with an average lifetime work effort of 40 hours per week.

The cyclical dynamic in labor market risk $\sigma_{n, 0}=15.9 \% ; \sigma_{n, 1}=8.4 \%$. Empirical findings by Storesletten, Telmer, and Yaron (2004) ${ }^{9}$ show the corresponding volatility of the transitory shock $\sigma_{u}$ is $32.9 \% .{ }^{10}$ The correlation between stock returns and permanent and transitory earnings shocks $\phi$ for both cases is set to zero, consistent with empirical evidence provided by Cocco, Gomes, and Maenhout (2005). The Social Security benefit structure is similar to that in effect in the United States. The benefit replacement rate $\zeta$ is set to 0.52 as per Mitchell and

\footnotetext{
${ }^{6}$ For computations, we use a grid of dimension $40(\mathrm{~W}) \times 30(\mathrm{P}) \times 2(\mathrm{~s}) \times 42(\mathrm{t})$ before and $40(\mathrm{~W}) \times 30(\mathrm{P}) \times 2(\mathrm{~s}) \times$ $39(\mathrm{t}) \times 9(\tau)$ after the ERA. For each grid point we evaluate the policy and value functions using Gaussian quadrature integration and cubic-splines interpolation.

${ }^{7}$ See http://www.bea.gov/national/index.htm.

${ }^{8}$ Storesletten, Telmer, and Yaron (2004) use the same transition matrix.

${ }^{9}$ Cocco, Gomes, and Maenhout (2005) and Storesletten, Telmer, and Yaron (2004) use PSID data and the same definition for labor income risk estimation. Therefore the difference in shock parameters can be reduced to the model settings, either including or excluding the business cycle. This is relevant for our later comparis ons.

10 The transitory shock volatility is divided by 2 to avoid estimation error.
} 
Phillips (2006); the actuarial reduction rate for early retirement benefits is $g_{1}=0.0713$, the delayed retirement crediting rate is $g_{2}=0.077$, and the normal retirement age is 65 , as in Buchinsky, Rust, and Benitez-Silva (2000) and Chai et al. (2009). Social Security benefits are taxed at a rate of $15 \%$ as in Gomes, Kotlikoff, and Viceira (2008). Housing-related expenditures $q_{t}$ are modeled as in Gomes and Michaelides (2005).

The annual real value-weighted market index portfolio returns on the NYSE, AMEX, and NASDAQ (from CRSP) from 1950 to $2008^{11}$ are classified into two states which are identified by the GNP growth rate. Then the parameters specifying the normal distribution of log gross return are given as follows: $\mu_{0}=6.84 \%, \sigma_{0}=11.21 \%, \mu_{1}=2.12 \%$, and $\sigma_{1}=20.77 \%{ }^{12}{ }^{13}$, equivalent to a yearly expected gross real return of 1.0775 and standard deviation of $12.12 \%$ in the expansion period, and 1.0437 and $21.91 \%$ in the contraction phase. Here, the expansion/contraction economy tends to coincide with a low/high-volatility, high/low-mean regime in the stock market. This evidence is also be found in Ang and Bekaert (2002), Gordon and St-Amour (2000), Guidolin and Timmermann (2008), and Kim and Lee (2007). The correlation between stock return and permanent shock is set to zero. Returns on assets are assumed to be taxed at 20\%; labor earnings are taxed at 30\% following Gomes, Kotlikoff, and Viceira (2008).

For the average household age 55, we estimate a wealth to income ratio of 9, which approximately represents the median of the wealth distribution. To this end, we draw on wealth data from Gustman, Steinmeier, and Tabatabai (2010) and income data from the SSA. Specifically, we employed the distribution of assets by wealth deciles in 2006 for households with at least one member born from 1948 to 1953, defining wealth as total wealth net of Social Security and Defined Benefit wealth. To estimate median labor income for households aged 55, we use SSA data on the median income of non-married persons aged 65-69 in the year 2006. We match labor income profiles estimated by Storesletten, Telmer, and Yaron (2004) to this income data and calculate the income at age 55 based on those profiles. Moreover, we assume that households aged 55 have not yet purchased any annuities.

\footnotetext{
${ }^{11}$ The US Consumer Price Index (CPI) from Datastream for the years 1950-2008 is used to get the real number.

12 To account for equity premium puzzle (too high historical equity premium), the expected average gross discrete real return is calculated by subtracting $1.73 \%$ fro $m$ the historical estimated mean value so that the equity premium is equal to $4 \%$.

${ }^{13}$ A Jarque-Bera test from the Matlab-statistic toolbox is applied to test the normal distribution at each observable regime. The null hypothesis of normal distribution cannot be rejected at a $5 \%$ significance level. The critical values are computed using Monte-Carlo simulation for small sample sizes.
} 


\section{Results}

Having solved the life-cycle problem for the optimal policies (consumption, asset allocation, work hours, saving, and retirement behavior), next we evaluate the distribution of decision variables based on a Monte Carlo simulation of 100,000 life-cycle trajectories, differentiating between two general economic and financial scenarios: crisis and normalcy.

\subsection{Identifying the Tails of the Financial/Economic Distribution}

To this end, we characterize a financial/economic crisis as one where the economy is in the contraction state for four years in a row, and in addition, in the first year the stock return is a minus 30\%. By contrast, a normal financial and economic environment, which we treat as the baseline scenario, is defined as one in which no additional exogenous restrictions are imposed on the state of the business cycle or the stock market performance. Hence, the initial state of the business cycle is determined by the (unconditional) long-run state probabilities and the states in subsequent periods by the conditional state transition probabilities, while stock market returns are governed by the business cycle state-specific distributions as described above.

In addition to this general analysis using the whole simulation sample, we are also keenly interested in the distributional tails. We examine these by analyzing subsamples of those 100,000 life-cycles, as not all households may be affected similarly by the business cycle; some perform exceptionally well, while others who experience unemployment and persistent wage shocks fare far worse. Accordingly, we stipulate that an individual suffers from a 'triple whammy' if he experiences a financial/economic crisis at the beginning of the analysis, is unemployed in at least two of the first four years thereafter, and also suffers from below-first quartile cumulated stock market returns until age 62 when he becomes eligible for Social Security benefits. By contrast, we define a doubly fortunate individual as someone that never experiences a financial/economic crisis, is never unemployed to age 62, and experiences above-average capital market returns to age 62 with cumulated stock returns in the top 25 percentile.

In what follows, we differentiate between the short- and long-term effects of the financial/economic crisis on households' behavior and wellbeing. While short-term effects can be studied using already available empirical data, sample data on the crisis' long-term effects will obviously not be available for several decades. For this reason, model simulations are the only way to make predictions about what future outcomes might be. Of particular interest in this context is how different cohorts are influenced by, and react to, the economic/financial crisis. While over the short run both younger and elder cohorts could be substantially affected by the crisis, due to their longer remaining period of economic activity, younger people might suffer less in the long run than do elder generations. To explore this outcome, we conduct our analyses 
for households that are hit by a financial/economic crisis at ages 20 and 55. For the cohort aged 20 (55), out of the 100,000 sample paths, we identify 933 (979) that qualify for the double fortune scenario and 1321 (1355) that comply with the triple whammy scenario.

\subsection{Short-term Effects}

We next turn our attention to the impacts of and the reaction to an economic/financial crisis over the short run, which in this study we define to cover a period of a decade. Figures 1 and 2 depict the effects for households initially age 20 or 55 on key decision variables: expected work hours (Panel A), consumption (Panel B), saving/withdrawal (i.e., labor income/Social Security benefits after taxes and housing expenditures minus consumption, Panel C), and stock investment (Panel D). Here, the solid black line presents absolute values for the normal scenario (left axis), while the bars show relative deviations from the base case results for three alternative scenarios: crisis (light grey), double fortune (black), and triple whammy (dark grey) on the right axis.

Figures 1 and 2 here

\subsubsection{Short-term Effects for the Younger Cohort}

In the base case scenario, the work effort of a young individual exceeds 40-hours per week, with average work effort starting at 47 hours per week at age 20 and then rising further to above 51 hours in the mid-20s (Figure 1, Panel A). Long and rising work hours, combined with a wage rate increasing with age and experience, generate high and rising labor income. This allows the individual to increase consumption from $\$ 9,000$ at age 20 to about $\$ 14,000$ in the mid-20s (Figure 1, Panel B). At the same time, periodic savings more than double from $\$ 1,600$ to about $\$ 3,700$ (Figure 1, Panel C). At age 20, the household will on average invest about $65 \%$ of liquid funds accumulated in stocks and increase this fraction over the following six years to almost 100\% (Figure 1, Panel D). The young household seeks high stock fractions due to the rather bond-like nature of labor income. Yet the minimum required investment amount for participating in the stock market results in stock fractions falling short of $100 \%$ early in the life-cycle, as sufficient funds must first be accumulated. Once a sufficient amount of liquid assets has been saved, the investor then maximizes equity exposure. With wage rates increasing even further and invested funds starting to generate measurable returns, the individual can afford to enjoy more leisure by already slightly reducing work hours in his late 20s, initiating the oft-cited humpshape in work effort. Both consumption and periodic saving increase further to about $\$ 17,400$ and $\$ 4,100$ by age 30 .

When we compare this baseline to a young household experiencing a financial and economic crisis at age 20, work effort proves to be virtually identical as a result of two offsetting 
effects. The crisis lowers wage rates resulting from higher unemployment probabilities, leaving the individual less inclined to work and more likely to consume leisure (by the substitution effect). Yet lower income provides less consumption opportunity which induces greater work effort (by the income effect). As work effort does not rise beyond base case, the individual compensates for his income drop by reducing both consumption and saving. Moreover, these reductions persist over the next decade even if the economy eventually recovers; consumption drops by $2 \%$ and periodic saving by $2-3 \%$ compared to the normal scenario. Not yet having accumulated financial assets, the young individual does not suffer from the $30 \%$ downturn in the stock market at the beginning of the financial and economic crisis, so his stock holdings are hardly affected, only dropping slightly (2.5\%) in the first two years.

By comparison, a young worker hit by a triple whammy will substantially reduce work effort. His hours worked per week drop by almost $10 \%$ in the first two years, compared to the base case, after which they slowly rise again. The corresponding drop in income drives a consumption decline of about $15 \%$ over the first four years. Periodic saving is even more affected, dropping by more than $60 \%$ for a worker in his early 20 s. Having so few liquid assets, the worker cannot afford to participate in the stock market, and overall stock fractions drop by $10-20 \%$ during the first five years (from a low base). After four year's time, as the initial crisis wanes, the individual strives to recover by increasing work effort above that in the base case over the second half of the decade. While consumption again converges toward the base case level, even at age 30 , it remains about $2 \%$ less than in the normal scenario. At the same time, the household seeks to replenish accumulated funds by saving between $10-20 \%$ more than the base line investor from the mid through late 20s. Once sufficient funds have been built up again, the household can then afford to invest in equities and stock holdings converge to those in the normal scenario from the mid-20s.

Finally, the doubly fortunate are even inclined to work slightly more in the early-20s than our base line households, which enables them to consume about 2-3\% more; this is the result of never being unemployed and not confronting a financial/economic crisis. Additionally, these individuals save substantially more, which increases their ability to early invest in stocks. With above average labor income and capital market performance, they can reduce their work effort even more than the baseline households in their late 20s, while still being able to afford 2-3\% higher consumption.

\subsubsection{Short-term Effects for the Near-Retirement Cohort}

Next we turn to our attention to the cohort looking ahead to retirement, initially age 55. In the baseline scenario, people reduce their work effort into their late 50s and early 60s, 
following the conventional hump-shape work pattern. At age 55, on average, they still engage in near full-time employment, but work hours per week gradually taper to 20 by age 65 (Figure 2, Panel A). As in the case of the younger cohorts, older people who experience the financial/economic crisis maintain a virtually identical work effort path.

The picture changes, however, when looking at households hit by the triple whammy. The near-retirement cohort - with a shorter period of economic activity remaining -- must compensate for reductions in wage rates and wealth by immediately increasing work hours. (It will be recalled that the younger cohort can work less, counting on a longer time horizon over which it can recover income losses.) Consequently, older persons' work effort rises by around $10 \%$ relative to the base case, and in their 60 s, the difference is greater, about $25 \%$. Sensibly, the doubly fortunate workers cash in on their luck in both the labor and capital markets by substantially reducing work effort sooner.

In the base case, the older cohort consumes about $\$ 30,000$ per year on average, or two to three times the consumption of households in their 20s. This consumption level is financed, to a large extent, by drawing down liquid financial assets (Figure 2, Panels B and C). Those older persons beset by a financial/economic crisis reduce annual consumption by around $4 \%$ per year from age 55 to 65, and annual withdrawals fall by about 2-3\%. Those hit by a triple whammy experience substantial and persistent reductions in annual consumption of about $10 \%$ compared to the base case. Early in the crisis, workers seek to maintain consumption by withdrawing almost 30\% more from liquid assets, compared to the base case. As financial wealth was already heavily battered due to the stock market downturn at the beginning of the crisis, these high withdrawals can only be maintained over a short period. Subsequently, withdrawals must be reduced by $30 \%$ more than the base case between the late 50 s and mid 60s. Consumption can only be maintained by substantially increasing work effort.

In our base case, as is typical in life-cycle models, the fraction of financial wealth invested in stocks, around $80 \%$ in the mid-50s, is below that early in working life, but it slightly increases again toward retirement age as the worker's exposure to labor market shocks declines. Given a financial/economic crisis, equity exposure falls short of the base case value by over $20 \%$ during the first four years; thereafter, after the initial crisis is over, stock fractions again converge. For those hit by the triple whammy, the change in the stock fraction compared to the base case traces out an S-shape. Early in the crisis, stock allocations drop by about $10 \%$, but from the late-50s it exceeds that of base case households by about $10 \%$. Anticipating a high probability of poor stock market performance in the following period, the household is less inclined to hold equities over the first years of the crisis. Later, low remaining financial wealth 
provides incentives to gamble and invest more in the stock market. Finally, doubly fortunate workers have persistently lower stock fractions over the entire period under scrutiny. Having accumulated high financial wealth allows the household to invest more conservatively.

In sum, for both younger and older cohorts, the financial/economic crisis has hardly any short-term impact on work effort on average. But a subset of people fares far worse, including near-retirees hit by a triple whammy who face a hostile labor market environment and also suffer substantial losses in financial wealth. Since they only have a few work years available to adjust to these shocks, they must immediately and significantly increase their work effort. By contrast, those hit at the beginning of their work lives must optimally reduce work hours in the less favorable labor market environment. The same conclusion holds for consumption on average: the impact of the financial/economic crisis is comparable for younger versus older cohorts. Yet older households hit by the triple whammy experience persistent consumption shortfalls, which are mitigated for the younger cohort where consumption converges to the base case level in time. The same holds for saving at young ages and withdrawals near retirement. And most striking is the difference in household allocations to stocks. Near-retirees have already accumulated financial wealth, and hence are more vulnerable to equity fluctuations, while the young have accumulated little in the way of financial assets. For this reason, the financial/economic crisis has little impact on the young, but near-retirees will optimally cut their equity exposure by over $20 \%$ during the crisis. This depends on the nature of the shock, however, since near-retirees hit by the triple whammy will invest more in stock, hoping to hit high returns.

\subsection{Long-tem Effects}

Next, we turn our attention to the impacts of and the reaction to an economic/financial crisis in the long run (i.e., over the remaining lifecycle). Findings are presented in Figures 3-4 and Tables 1-4. Figure 3 depicts expected work hours (Panel A), consumption (Panel B), and saving/withdrawal (i.e., labor income/Social Security benefits after taxes and housing expenditures minus consumption, Panel C) for the younger cohort. Again, the black line presents absolute values for the baseline or normal scenario (left axis), while the bars show relative deviations from the base case for the alternative scenarios (right axis): crisis (light grey), double fortune (black), and triple whammy (dark grey). Panel C distinguishes between saving (solid black line) and withdrawal, i.e., negative saving (dashed black line). Figure 4 presents consumption (Panel A) and withdrawal (Panel B) for the near-retirement cohort. Work hours for this cohort are omitted as households in this cohort will all have retired over the longer run. Tables 1 and 2 show retirement behavior for both cohorts and Tables 3 and 4 present their longterm asset allocations. 


\section{Figures 3 and 4, and Tables 1-4 here}

\subsubsection{Long-term Effects for the Younger Cohort}

Looking at the cohort of persons first experiencing a shock at age 20, it is clear that patterns that already emerged in the later years of our short-term analysis of work effort continue to persist over the longer run (Figure 3, Panel A). Our base case household in a normal scenario will gradually reduce weekly work hours from about 50 at age 30 , to around 25 by age 60 . As in the short-term case, the long-term effects of the financial/economic crisis on work effort are negligible. By contrast, doubly fortunate households reduce their level of work effort below that of base case households, by about $10 \%$ at age 45 , and $20 \%$ at age 55 . Those hit by the triple whammy, however, must boost work hours substantially compared to the base case, by about $10 \%$ at age 50 , and $20 \%$ at age 60 . Hence, work effort at these ages is still as high as that of base case households that are five years younger.

Turning to lifetime effects on consumption (Panel B, Figure 3), we find that under the normal scenario, consumption grows to age 60 and peaks at an annual \$30,500. Subsequently, households start to retire and substitute less goods consumption with more leisure time consumption. ${ }^{14}$ Doubly fortunate households can substantially increase their consumption level relative to the normal scenario, by $17 \%$ during their 70 s and still by $15 \%$ at age 90 . Crisis households, however, experience a persistent consumption reduction of $2 \%$, and those going through a triple whammy have $3 \%$ shortfalls over their work lives. Though the latter are surely financially worse off, due to poor capital market performance, they can maintain much of their consumption by working more. Later in life, however, they lose this flexibility and hence suffer from higher consumption shortfalls, of around $10 \%$ at age 70 .

Wealth patterns are also different. Base case households continue to build up financial wealth until their 40s (Figure 3, Panel C); from their 50s onward, they begin drawing down assets to pay for high and still increasing consumption while already reducing work effort. Apparently, as consumption reaches its peak at age 60, so do withdrawals with a maximum value of $\$ 12,500$ per annum. A worker who started his work life in the crisis will save about $4 \%$ less than base case households by age 30; over the next decade, he must boost saving to ensure sufficient financial reserves for the withdrawal phase, so by age 40 , saving exceeds that of base case households by about 5\%. Later in the life-cycle, withdrawals are similar to the normal scenario. Doubly fortunate households can afford to save less and withdraw more than the base case household due to their above-average labor and capital market performance. For those experiencing the triple whammy, obviously, the opposite is true and they have to save more and

\footnotetext{
${ }^{14}$ This accords with empirical evidence regarding pre/post consumption patterns in Aguiar and Hurst (2005).
} 
invest less.

Table 1 depicts how the younger cohort allocates financial wealth to liquid stocks and bonds, as well as to illiquid life annuities over the life cycle. First, in the normal scenario, we see a typical stock fraction path over the life cycle. The young household is almost fully invested in stocks by age 30, and over time he reduces equity exposure near retirement to well below $80 \%$. Initially, stocks are substituted by bonds which make up about $20 \%$ of the portfolio by age 50 . As the survival credit and, hence, the excess return of annuities over bonds increases with household age, annuities start to crowd out bonds, making up about $14 \%$ of the portfolio by age 70. At older ages, the individual gradually depletes his liquid financial wealth and lowers his stock fraction to $34 \%$ by age 80 ; the share of annuities in the allocation of overall financial wealth increases to about half. Even at age 80 , the investor optimally holds over $16 \%$ of financial wealth in bonds, despite the fact that annuities substantially outperform liquid bond holdings. The reason is that, as liquid assets are consumed, it becomes more and more difficult for the household to meet the minimum requirement on stock investments. Accordingly, bonds increasingly represent the only sensible liquid asset held by the household.

Comparing the crisis setting to our base case scenario, we find hardly any differences, indicating that the long-term effects of the crisis on workers' asset allocations are negligible when the impact strikes young, as these individuals lack financial assets. By contrast, experiencing the triple whammy young does have a life-long impact. Young workers with very low financial wealth have only one major asset, their bond-like human capital, so they are much more likely to hold more stock over their lifetimes. In their 60s, for example, they still invest over $85 \%$ of financial wealth in equities. The opposite is true for the doubly fortunate households, who invest less in equity over the whole life-cycle. Their bond-like labor income makes up a smaller part of their overall wealth, leading them to diversify by shifting a higher share of financial wealth into less risky assets (i.e., bonds earlier in life, and later, annuities).

It is also of interest to ask how the crisis shapes retirement behavior. Table 2 presents the fraction of households that retire from age 62-70 (retiring is defined by reducing work effort to below 20 hours per week). The base case setting exhibits the empirically well documented twopeaked distribution: over one-quarter of households retires at the early retirement age of 62, while around half retire later, at ages 66 and 67. By age 68, all households have retired, and on average, retirement occurs at age 64.8. Workers struck by the crisis at a young age have several decades to adjust, and they make retirement timing decisions virtually identical to those of base case households (resulting in the same average retirement age). By contrast, young workers experiencing a triple whammy when young must work longer to make up the shortfall: three- 
quarters postpone retirement beyond the normal retirement age, and on average they retire one year later than the base case scenario, at age 65.8. Not surprisingly, half of the doubly fortunate group retires as early as possible; 70\% leave work prior to normal retirement age, twice as high as in the base case, which drives down the average retirement age by more than a year (to 63.5).

\subsubsection{Long-term Effects for the Older Cohort}

Our base case households in the normal scenario consume about $\$ 31,000$ at age 65 on average, and reduce their spending over the following two decades to around $\$ 22,000$. After that, consumption increases again (Figure 4, Panel A). Being exposed to a financial/economic crisis leaves households with lower financial wealth as well as lower Social Security income. Consequently, retirement consumption falls short of that of base case households by $4 \%$ per year. Households hit by the triple whammy close to retirement suffer dramatically over the remaining life-time, as consumption persistently drops by 11-18\%. By contrast, doubly fortunate households enjoy consumption that exceeds base case levels by $8-15 \%$. Consumption is predominantly financed through constant Social Security income, to about $80 \%$ from age 75 on. The remainder must be supported by withdrawals from financial wealth that, consequently, exhibit the same temporal pattern as consumption, yet with higher magnitude due to the base effect (Figure 4, Panel B).

Long-term asset allocation patterns for the older cohort appear in Table 3. Under all scenarios, stock fractions decrease over time as the household gradually depletes liquid financial wealth, from $80-95 \%$ at age 65 , to $24-38 \%$ at age 85 . Bond fractions decline through the 60 s, increase again through the 70s, and peak in the early 80s, when due to diminishing liquid wealth, households increasingly face difficulties to finance the minimum amount required to participate in the stock market. To take advantage of the increasing survival credit, households gradually shift financial wealth from liquid assets into annuities. When combined with the depletion of liquid assets due to consumption-financing withdrawals, this drives annuity fractions up from $0.2-5 \%$ at age 65 to $45-64 \%$ at age 85 . In general, compared to the base case calibration, the allocation to liquid assets is marginally higher under the crisis scenario and substantially higher for triple whammy households. The asset allocation of doubly fortunate households, on the other hand, is characterized by lower stock and higher annuity fractions.

Finally, Table 4 summarizes the impact of the financial/economic crisis on retirement patterns of the older cohort. In the baseline case, the average retirement age is 65.1; one fifth of all households (20.6\%) retire at the early retirement age 62; about half (51\%) at age 66-67, and the remainder (5.1\%) at age 68 . In the crisis scenario, the fraction of households retiring at the early retirement age drops by $2.4 \%$, and that of households retiring prior to the normal retirement 
age of 65 drops by a mere $0.4 \%$; this produces a tiny increase in the average retirement age of only 0.07 years (a little less than a month). Things are very different for those individuals who experienced the triple whammy: almost 90\% cannot afford to retire before the normal retirement age, which drives up the average retirement age by 1 year compared to the normal scenario. Two of five doubly fortunate households retire at the early retirement age, and three of five retire prior to the normal retirement age; consequently, the average retirement age falls by about 1 year compared to the base case scenario. Under all scenarios, the latest retirement age is 68 .

\section{Conclusions}

Our goal was to investigate the short- and long-term impacts of a combined financial and economic crisis on households at different stages in their life-cycles. To this end, we have developed a life-cycle model that allows for optimal consumption, work effort, retirement, asset allocation, and annuitization decisions, incorporating countercyclical labor income and unemployment risk as well as regime shifts in the investment opportunity set. We show that for young households, the financial/economic crisis will have little impact on either work effort or retirement behavior, though they do suffer from a long-term decline in annual consumption accompanied by lower saving. Stock fractions are marginally lower at the onset of the crisis, but over the remaining life-cycle, asset allocation does not change much.

Young households hit particularly badly by the financial/economic crisis do have more response, reducing their work effort during the crisis by up to $10 \%$; later in life, they must boost work hours substantially - over $20 \%$ at age 60 compared to the non-crisis scenario, and must defer retirement by one year on average. Lifetime consumption is also lower: in their early 20s, it is about $15 \%$ less, and $5 \%$ less even after age 70 . The other effect is that young households must save substantially more than non-crisis households later in life, to build up at least some financial wealth. Low savings early in life go hand in hand with low stock investment; thereafter, from about age 40 on, equity exposure is continuously higher than that of non-crisis households, while both bond investments and annuity purchases are reduced.

When older persons are hit by a combined financial and economic crisis, they are predicted to boost work effort slightly, around $0.3-1.3 \%$, over the rest of their work lives. Moreover, their average retirement age rises slightly as well (less than one month). The crisis is felt, instead, in more marked declines in annual consumption, both short- and long-term. Compared to a non-crisis scenario, consumption drops by 3.5\% before retirement and by around $4.5 \%$ after age 80 . Households reduce their asset withdrawals by about $2.5 \%$ over the short-run and by about $9 \%$ later in life. During the immediate crisis, households reduce their equity 
exposure by more than 20\%, on average, in favor of risk-free bonds. Over the longer run, however, investors have a marginally higher appetite for liquid assets, both stocks and bonds, than investors in a non-crisis scenario. Consequently, the level of annuitization decreases.

Those older households hit especially badly by unemployment and stock market shocks must substantially boost their work effort, by over $20 \%$ in their early 60s. Moreover, they cannot afford to retire early and must postpone retirement by about 1 year, on average. Yet they still experience consumption losses of about $10 \%$ in the short-term and about $15 \%$ later in life. While they are able to dampen the immediate impacts of the crisis through an increase in withdrawal of financial assets (about 30\% at age 55), the corresponding drop in financial wealth results in substantial cuts in withdrawals later in life (more than $40 \%$ from age 70 ). These households reduce their equity exposure only by $10 \%$ early in the crisis. Over the remaining life-cycle, allocation to stocks is substantially higher than that of households in the non-crisis scenarios.

Our predictions that older households must curtail their consumption, boost work effort, and defer retirement correspond to recent evidence on short-term effects of the crisis on older individuals (Gustman, Steinmeier, and Tabatabai, 2010; Hurd and Rohwedder, 2010; Shapiro, 2010). For younger cohorts, on the other hand, there are (to the best of our knowledge) no empirical studies on how they are responding to the crisis in the short term. And for obvious reasons, it will take years to trace out how the crisis will influence long-term work, saving, consumption, and investment behavior. Our research offers a valuable means for informing policymakers about how such crises can differentially influence household responses to economic shocks, as they deploy the adjustment mechanisms at their disposal. Based on the framework provided, subsequent work can evaluate how policy changes might enhance wellbeing in the face of such crises, for instance by making the retirement process more versus less flexible, supporting annuitization of retirement assets, or by changing retirement ages under Social Security. 


\section{References}

Aguiar, M. and E. Hurst. (2005). Consumption vs Expenditure. Journal of Political Economy 113, 5 (October): 919-948.

Ang, A. and G. Bekaert (2002). International Asset Allocation with Regime Shifts. Review of Financial Studies 15, 1137-87.

Bosworth, B., G. Burtless and G. Steuerle. (2000). Lifetime Earnings Patterns, the Distribution of Future Social Security Benefits, and the Impact of Pension Reform. Social Security Bulletin, 63(4), 74-98.

Brown, J., O. S. Mitchell, J. Poterba, and M. Warshawsky. (1999). Taxing Retirement Income: Nonqualified Annuities and Distributions from Qualified Accounts. National Tax Journal. LII3, 563-592.

Buchinsky, M, Rust, J. and Benítez-Silva, H (2000). Dynamic Structural Models of Retirement and Disability. Yale University Department of Economics Working Paper.

Carroll C. D. and Dunn, W. E. (1997). Unemployment Expectations, Jumping (S,s) Triggers, and Household Balance Sheets. NBER Macroeconomics Annual.

Chai, J., W. Horneff, R. Maurer, and O. S. Mitchell (2009). Extending Life Cycle Models of Optimal Portfolio Choice: Integrating Flexible Work, Endogenous Retirement, and Investment Decisions with Lifetime Payouts. NBER Working Paper Nr. 15079.

Cocco, J., F. Gomes, and P. Maenhout (2005). Consumption and Portfolio Choice over the Life Cycle. Review of Financial Studies 18, 491-533.

Coile, C., P.Diamond, J.Gruber, and A.Jousten. (2001). Delays in Claiming Social Security Benefits. Journal of Public Economics 84: 357-385.

Fehr, H., S. Jokisch, and L.J. Kotlikoff . (2006). Will China Eat our Lunch or Take Us Out to Dinner? Simulating the Transition Paths of the US, EU, Japan and China. In: Takatoshi Ito and Andrew K. Rose (Eds.). Fiscal Policy and Management in East Asia. Chicago, University of Chicago Press, 133-198.

Gomes, F., L. Kotlikoff, and L.M. Viceira (2008). Optimal Life-Cycle Investing with Flexible Labor Supply: A Welfare Analysis of Life-Cycle Funds. American Economic Review: Papers \& Proceedings 98, 297-303.

Gomes, F., and A. Michaelides (2005). Optimal Life-Cycle Asset Allocation: Understanding the Empirical Evidence. Journal of Finance 60, 869-904.

Gordon, S., and Pascal St-Amour, (2000). A Preference Regime Model of Bull and Bear Markets. American Economic Review 90, 1019-1033.

Guidolin, M., and Allan Timmermann (2008). International Asset Allocation under Regime Switching, Skew, and Kurtosis Preferences. Review of Financial Studies 2, 889 - 935.

Gustman, A.L., T.L. Steinmeier, and N. Tabatabai (2010). What the Stock Market Decline Means for the Financial Security and Retirement Choices of the Near-Retirement Population. Journal of Economic Perspectives 24 (1), 161-182.

Hurd, M. and S. Rohwedder (2010). The Effects of the Economic Crisis on the Older Population. MRRC-WP 2010-231. Health and Retirement Study(HRS), 2006 and 2008.

Kim, S., and B. Lee, (2007). Stock Returns, Asymmetric Volatility, Risk Aversion, and Business Cycle: Some new Evidence. Economic Inquiry, 46, 131 - 148.

Mitchell, O.S. and J. Phillips (2006). Social Security Replacement Rates for Alternative Earnings 
Benchmarks. Benefits Quarterly 4, 37-47.

OECD (2009). Pensions at a Glance: Retirement-Income Systems in OECD Countries. OECD: Paris.

Shapiro, M. D. (2010). The Effects of the Financial Crisis on the Well-Being of Older Americans: Evidence from the Cognitive Economics Study. MRRC Working paper. WP 2010-228.

Storesletten, K., C. I. Telmer, and A. Yaron (2004). Cyclical Dynamics in Idiosyncratic Labor Market Risk. Journal of Political Economy 112, 695-717.

Smetters, K. A. and Y. Chen (2010). Optimal Portfolio Choice over the Life Cycle with Social Security. Wharton School Working Paper.

US Bureau of Labor Statistics (BLS, 2010). Labor Force Statistics from the Current Population Survey. Viewed 7-2-10.

http://data.bls.gov/PDQ/servlet/SurveyOutputServlet?request_action=wh\&graph_name=LN_cpsbref3

Whitehouse, E. (2010). Pension During the Crisis: Impact on Retirement-Income Systems and Policy Responses. OECD. 
Figure 1: Short-term Effects of Financial/Economic Crises on Young Cohort (Age 20)
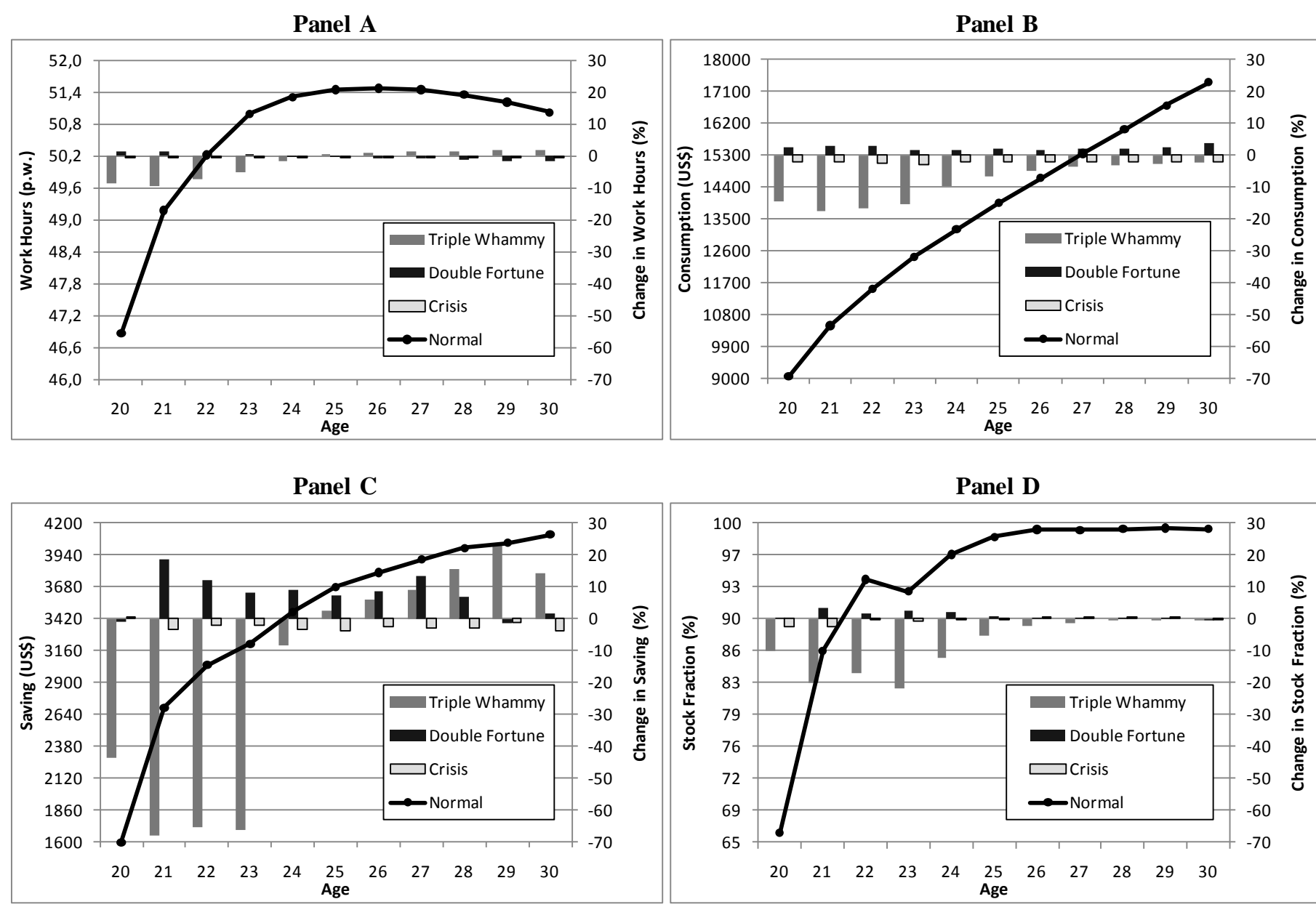

Notes: Panel A: Expected work hours. Panel B: Expected consumption. Panel C: Expected. saving/withdrawal (i.e., labor income/Social Security benefits after taxes and housing expenditures minus consumption). Panel D: Expected stock investment. Solid black line (axis on the left): Absolute values under normal scenario. Bars (axis on the right): Relative deviations from normal case for alternative scenarios: Crisis (light grey), Double fortune (black), Triple whammy (dark grey). Source: Authors' calculations. 
Figure 2: Short-tem Effects of Financial/Economic Crises on Near-retirement Cohort (Age 55)
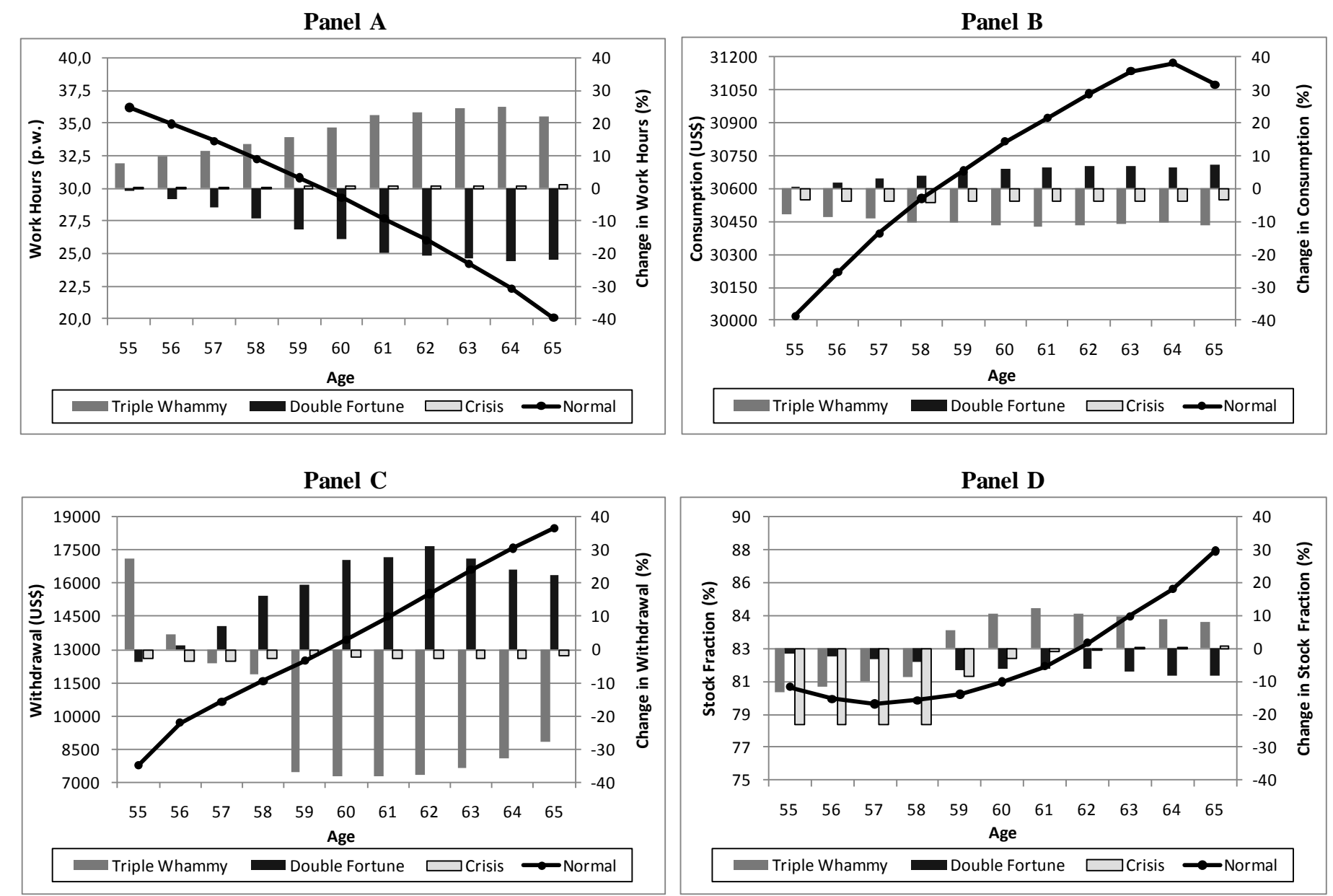

Notes: Panel A: Expected work hours. Panel B: Expected consumption. Panel C: Expected. saving/withdrawal (i.e. labor income/Social Security benefits after taxes and housing expenditures minus consumption). Panel D: Expected stock investment. Solid black line (axis on the left): Absolute values undernormal scenario. Bars (axis on the right): Relative deviations from normal case for alternative scenarios: Crisis (light grey), Double fortune (black), Triple whammy (dark grey). Source: Authors' calculations. 
Figure 3: Long-term Effects of Financial/Economic Crises on Young Cohort (Age 20)

\section{Panel A}

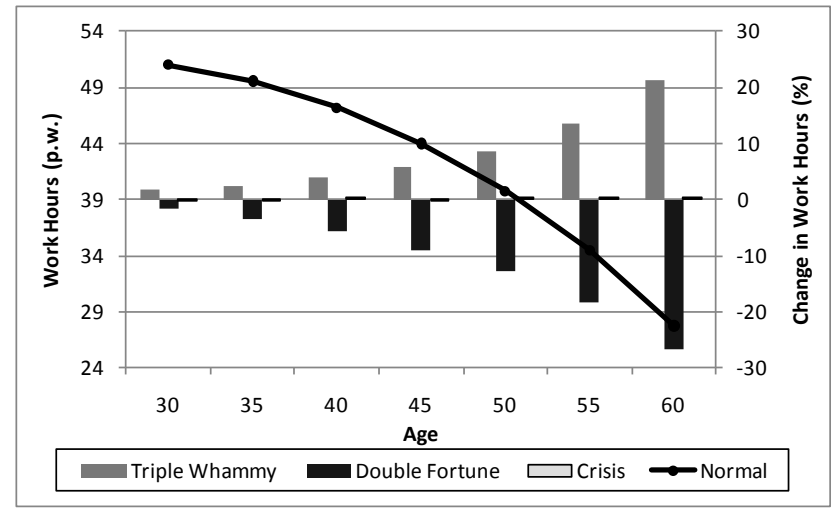

Panel B

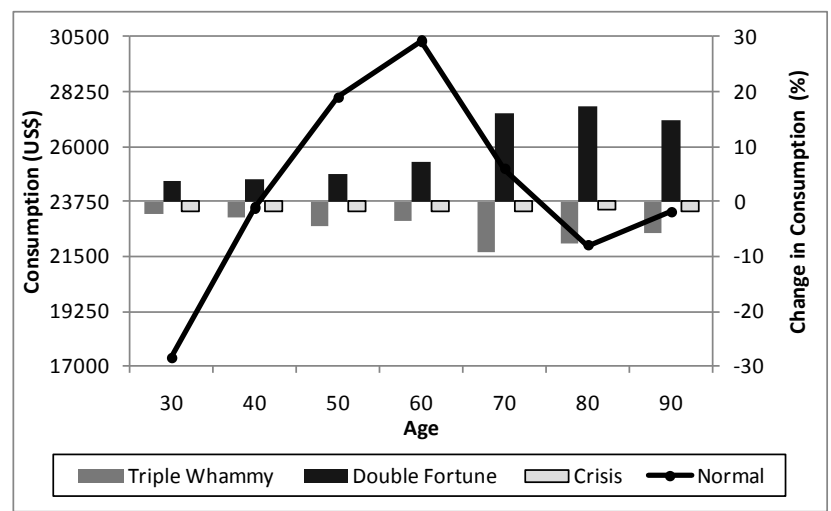

Panel C

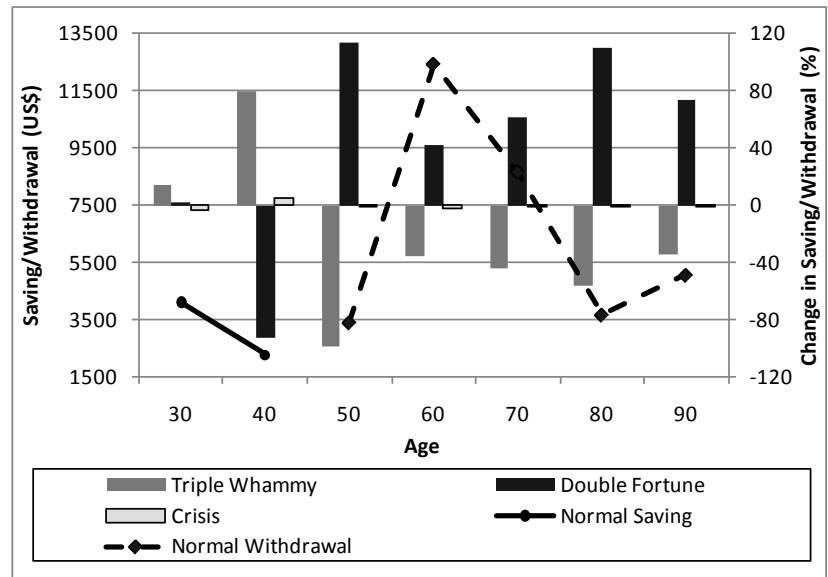

Notes: Panel A: Expected work hours. Panel B: Expected consumption. Panel C: Expected. saving/withdrawal (i.e., labor income/Social Security benefits after taxes and housing expenditures minus consumption). Solid black line (axis on the left): Absolute values under normal scenario. Bars (axis on the right): Relative deviations from normal case for alternative scenarios: Crisis (light grey), Double fortune (black), Triple whammy (dark grey). Source: Authors' calculations. 
Figure 4: Long-term Effects of Financial/Economic Crises on Near-Retirement Cohort (Age 55)

Panel A

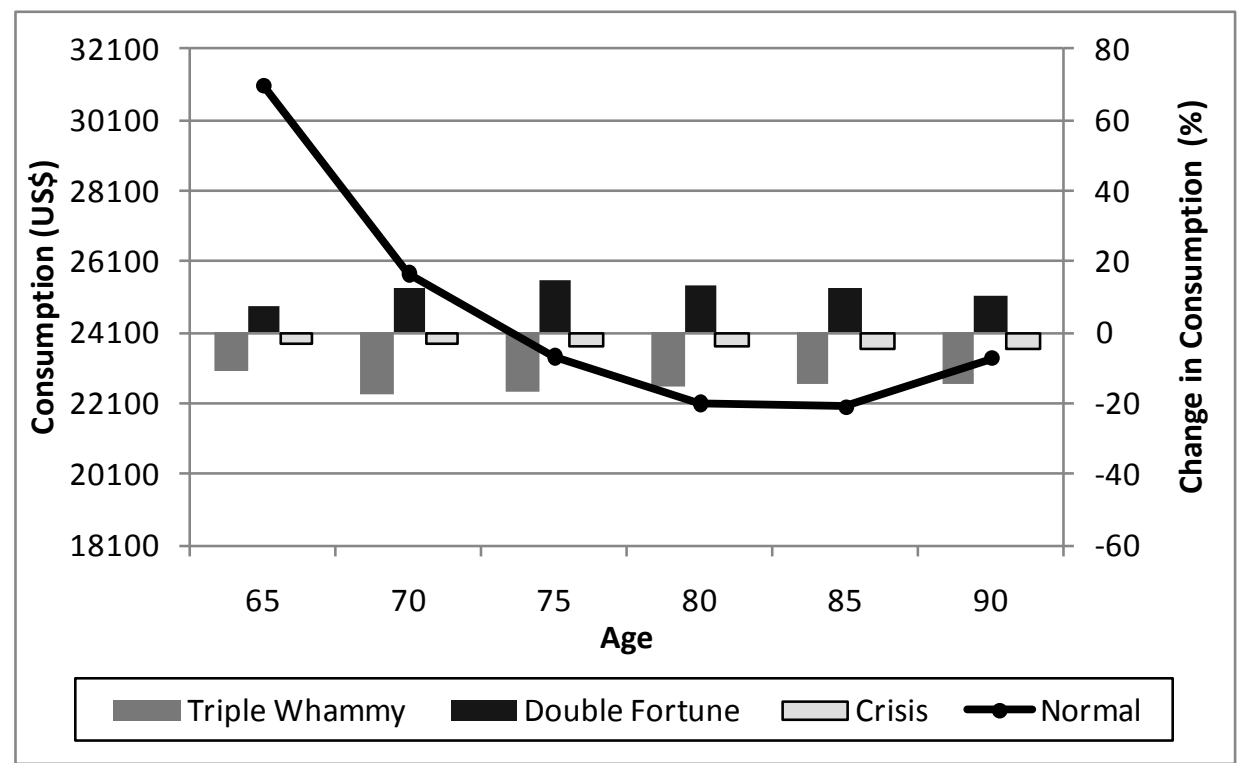

Panel B

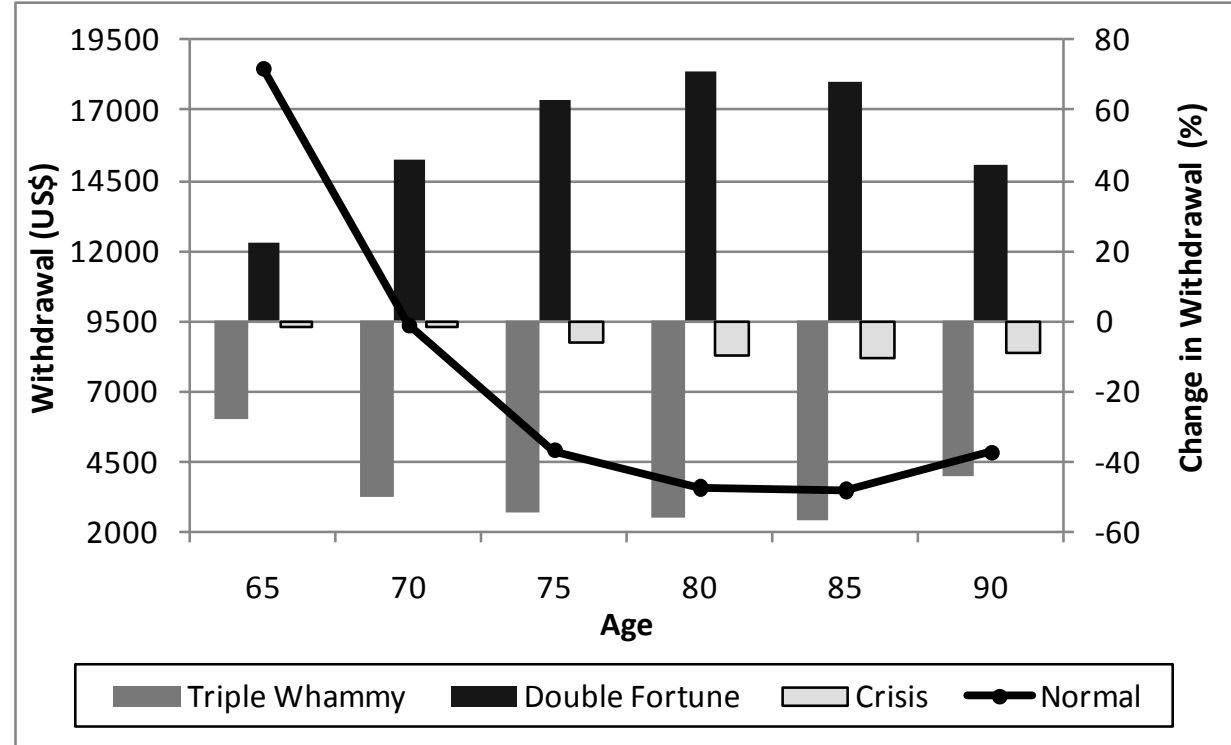

Notes: Panel A: Expected consumption. Panel B: Expected. withdrawal (i.e., labor income/Social Security benefits after taxes and housing expenditures minus consumption). Solid black line (axis on the left): Absolute values under normal scenario. Bars (axis on the right): Relative deviations from normal case for alternative scenarios: Crisis (light grey), Double fortune (black), Triple whammy (dark grey). Source: Authors' calculations. 
Table 1: Long-term Impacts of Crisis on Asset Allocation of Young Cohort (Age 20)

\begin{tabular}{|c|c|c|c|c|}
\hline \multirow[b]{3}{*}{ Age } & \multicolumn{4}{|c|}{ Asset Allocation (\%) } \\
\hline & \multicolumn{2}{|c|}{ Average } & \multicolumn{2}{|c|}{ Tails } \\
\hline & Normal & Crisis & $\begin{array}{l}\text { Double } \\
\text { Fortune }\end{array}$ & $\begin{array}{c}\text { Triple } \\
\text { Whammy }\end{array}$ \\
\hline & \multicolumn{4}{|c|}{ Stocks } \\
\hline 30 & 99.3 & 99.3 & 99.0 & 99.2 \\
\hline 40 & 90.0 & 90.0 & 84.3 & 94.5 \\
\hline 50 & 79.5 & 79.5 & 69.3 & 87.1 \\
\hline 60 & 77.3 & 77.3 & 66.3 & 86.7 \\
\hline 70 & 79.5 & 79.3 & 63.6 & 85.8 \\
\hline \multirow[t]{2}{*}{80} & 34.1 & 34.2 & 21.1 & 41.1 \\
\hline & \multicolumn{4}{|c|}{ Bonds } \\
\hline 30 & 0.6 & 0.7 & 1.0 & 0.7 \\
\hline 40 & 10.0 & 9.9 & 15.5 & 5.5 \\
\hline 50 & 19.3 & 19.3 & 25.7 & 12.7 \\
\hline 60 & 18.7 & 18.6 & 20.4 & 12.5 \\
\hline 70 & 6.7 & 6.7 & 6.0 & 8.1 \\
\hline \multirow[t]{2}{*}{80} & 16.5 & 16.5 & 11.3 & 23.1 \\
\hline & \multicolumn{4}{|c|}{ Annuities } \\
\hline 30 & 0.0 & 0.0 & 0.0 & 0.1 \\
\hline 40 & 0.1 & 0.1 & 0.2 & 0.0 \\
\hline 50 & 1.2 & 1.2 & 5.0 & 0.2 \\
\hline 60 & 4.1 & 4.1 & 13.4 & 0.8 \\
\hline 70 & 13.8 & 14.0 & 30.3 & 6.1 \\
\hline 80 & 49.4 & 49.3 & 67.6 & 35.8 \\
\hline
\end{tabular}

Notes: Source: Authors' calculations. 
Table 2: Crisis Impact on Retirement Behavior of Young Cohort (Age 20)

\begin{tabular}{|c|c|c|c|c|}
\hline \multirow[b]{3}{*}{ Age } & \multicolumn{4}{|c|}{ Retirement Ratio (\%) } \\
\hline & \multicolumn{2}{|c|}{ Average } & \multicolumn{2}{|c|}{ Tails } \\
\hline & Normal & Crisis & $\begin{array}{l}\text { Double } \\
\text { Fortune }\end{array}$ & $\begin{array}{c}\text { Triple } \\
\text { Whammy }\end{array}$ \\
\hline 62 & 27.4 & 27.4 & 53.9 & 8.0 \\
\hline 63 & 6.3 & 6.2 & 8.8 & 3.6 \\
\hline 64 & 6.6 & 6.5 & 7.3 & 5.5 \\
\hline 65 & 8.2 & 8.2 & 5.1 & 8.8 \\
\hline 66 & 24.6 & 24.5 & 12.6 & 36.3 \\
\hline 67 & 22.3 & 22.3 & 9.9 & 32.7 \\
\hline 68 & 4.7 & 4.8 & 2.1 & 5.1 \\
\hline 69 & 0.0 & 0.0 & 0.2 & 0.1 \\
\hline 70 & 0.0 & 0.0 & 0.0 & 0.0 \\
\hline Avg. Retirement Age & 64.82 & 64.82 & 63.53 & 65.80 \\
\hline
\end{tabular}

Notes: Fractions of households that retire at specific age. Definition of retirement: work effort reduced to below 20 hours per week. Source: Authors' calculations. 
Table 3: Long-term Impacts of Crisis on Asset Allocation of Near-retirement Cohort (Age 55)

\begin{tabular}{|c|c|c|c|c|}
\hline \multirow[b]{3}{*}{ Age } & \multicolumn{4}{|c|}{ Asset Allocation (\%) } \\
\hline & \multicolumn{2}{|c|}{ Average } & \multicolumn{2}{|c|}{ Tails } \\
\hline & Normal & Crisis & $\begin{array}{l}\text { Double } \\
\text { Fortune }\end{array}$ & $\begin{array}{c}\text { Triple } \\
\text { Whammy }\end{array}$ \\
\hline & \multicolumn{4}{|c|}{ Stocks } \\
\hline 65 & 88.1 & 88.7 & 80.6 & 95.2 \\
\hline 70 & 86.2 & 88.0 & 81.4 & 88.8 \\
\hline 75 & 64.3 & 65.7 & 59.0 & 69.3 \\
\hline 80 & 41.0 & 41.8 & 35.5 & 48.3 \\
\hline \multirow[t]{2}{*}{85} & 29.9 & 30.8 & 23.7 & 38.0 \\
\hline & \multicolumn{4}{|c|}{ Bonds } \\
\hline 65 & 9.9 & 10.2 & 14.4 & 4.6 \\
\hline 70 & 7.7 & 7.3 & 7.2 & 8.9 \\
\hline 75 & 13.0 & 13.1 & 12.6 & 13.6 \\
\hline 80 & 21.9 & 22.3 & 17.1 & 28.5 \\
\hline \multirow[t]{2}{*}{85} & 13.8 & 14.3 & 12.2 & 17.3 \\
\hline & \multicolumn{4}{|c|}{ Annuities } \\
\hline 65 & 2.1 & 1.1 & 5.0 & 0.2 \\
\hline 70 & 6.2 & 4.8 & 11.5 & 2.3 \\
\hline 75 & 22.6 & 21.3 & 28.4 & 17.1 \\
\hline 80 & 37.1 & 35.8 & 47.4 & 23.2 \\
\hline 85 & 56.2 & 54.9 & 64.2 & 44.7 \\
\hline
\end{tabular}

Notes: Source: Authors'calculations. 
Table 4: Crisis Impact on Retirement Behavior of Near-Retirement Cohort (Age 55)

\begin{tabular}{|c|c|c|c|c|}
\hline \multirow[b]{3}{*}{ Age } & \multicolumn{4}{|c|}{ Retirement Ratio (\%) } \\
\hline & \multicolumn{2}{|c|}{ Average } & \multicolumn{2}{|c|}{ Tails } \\
\hline & Normal & Crisis & $\begin{array}{l}\text { Double } \\
\text { Fortune }\end{array}$ & $\begin{array}{c}\text { Triple } \\
\text { Whammy }\end{array}$ \\
\hline 62 & 20.6 & 18.2 & 40.6 & 4.4 \\
\hline 63 & 7.0 & 7.4 & 9.3 & 3.3 \\
\hline 64 & 7.0 & 8.1 & 9.1 & 3.2 \\
\hline 65 & 9.0 & 9.5 & 8.7 & 10.2 \\
\hline 66 & 26.8 & 26.8 & 16.6 & 38.2 \\
\hline 67 & 24.4 & 24.7 & 13.0 & 33.2 \\
\hline 68 & 5.1 & 5.4 & 2.8 & 7.5 \\
\hline 69 & 0.0 & 0.0 & 0.0 & 0.0 \\
\hline 70 & 0.0 & 0.0 & 0.0 & 0.0 \\
\hline Avg. Retirement Age & 65.08 & 65.15 & 64.02 & 66.04 \\
\hline
\end{tabular}

Notes: Fractions of households that retire at specific age. Definition of retirement: work effort reduced to below 20 hours per week. Source: Authors' calculations. 